OPEN ACCESS

Edited by:

Predrag Sikiric,

University of Zagreb, Croatia

Reviewed by:

Pamela Del Carmen Mancha-Agresti,

Federal University of Minas Gerais,

Brazil

Oksana Zayachkivska,

Danylo Halytsky Lviv National Medical

University, Ukraine

${ }^{*}$ Correspondence:

Hans Lennernäs

hans.lennernas@farmbio.uu.se

Specialty section: This article was submitted to Gastrointestinal and Hepatic Pharmacology,

a section of the journal

Frontiers in Pharmacology

Received: 16 March 2021 Accepted: 19 April 2021 Published: 04 May 2021

Citation:

Dahlgren D, Sjöblom M, Hellström PM and Lennernäs $H$ (2021)

Chemotherapeutics-Induced Intestinal Mucositis: Pathophysiology and Potential Treatment Strategies. Front. Pharmacol. 12:681417. doi: 10.3389/fphar.2021.681417

\section{Chemotherapeutics-Induced Intestinal Mucositis: Pathophysiology and Potential Treatment Strategies}

\author{
David Dahlgren ${ }^{1}$, Markus Sjöblom ${ }^{2}$, Per M Hellström ${ }^{3}$ and Hans Lennernäs ${ }^{1 *}$ \\ ${ }^{1}$ Department of Pharmaceutical Biosciences, Uppsala University, Uppsala, Sweden, ${ }^{2}$ Department of Neuroscience, Division of \\ Physiology, Uppsala University, Uppsala, Sweden, ${ }^{3}$ Department of Medical Sciences, Gastroenterology/Hepatology, Uppsala \\ University, Uppsala, Sweden
}

The gastrointestinal tract is particularly vulnerable to off-target effects of antineoplastic drugs because intestinal epithelial cells proliferate rapidly and have a complex immunological interaction with gut microbiota. As a result, up to $40-100 \%$ of all cancer patients dosed with chemotherapeutics experience gut toxicity, called chemotherapeutics-induced intestinal mucositis (CIM). The condition is associated with histological changes and inflammation in the mucosa arising from stem-cell apoptosis and disturbed cellular renewal and maturation processes. In turn, this results in various pathologies, including ulceration, pain, nausea, diarrhea, and bacterial translocation sepsis. In addition to reducing patient quality-of-life, CIM often leads to dose-reduction and subsequent decrease of anticancer effect. Despite decades of experimental and clinical investigations CIM remains an unsolved clinical issue, and there is a strong consensus that effective strategies are needed for preventing and treating CIM. Recent progress in the understanding of the molecular and functional pathology of CIM had provided many new potential targets and opportunities for treatment. This review presents an overview of the functions and physiology of the healthy intestinal barrier followed by a summary of the pathophysiological mechanisms involved in the development of CIM. Finally, we highlight some pharmacological and microbial interventions that have shown potential. Conclusively, one must accept that to date no single treatment has substantially transformed the clinical management of CIM. We therefore believe that the best chance for success is to use combination treatments. An optimal combination treatment will likely include prophylactics (e.g., antibiotics/probiotics) and drugs that impact the acute phase (e.g., anti-oxidants, apoptosis inhibitors, and anti-inflammatory agents) as well as the recovery phase (e.g., stimulation of proliferation and adaptation).

Keywords: chemotherapeutics-induced mucositis, gastrointestinal physiology, intestinal proliferation, cancer, stem cells, toxicity, mucositis

\section{INTRODUCTION}

Chemotherapy is in general associated with extensive anti-tumor effects, but also serious adverse effects and long-term safety issues for both cancer patients and healthcare providers (Sougiannis et al., 2021). One of the more common off-target toxicities is chemotherapeutics-induced intestinal mucositis (CIM), which is a complex gastrointestinal (GI) complication. It affects up to $40-100 \%$ of all cancer patients 
dosed with chemotherapeutics, depending drug and dosing regimen (Sonis et al., 2015; Villa and Sonis, 2015). The GI tract is particularly vulnerable to antineoplastic drugs that inhibit cell growth and/or cell division, as the intestinal epithelial cells (IEC) proliferate rapidly and have a complex immunological interaction with the gut microbiota. For instance, antineoplastic drugs such as 5-fluorouracil, methotrexate, irinotecan, and doxorubicin target the vulnerable GI tissue by interrupting DNA synthesis, leading to apoptosis. An inability to resist damage and/or rapidly repair and restore the epithelial barrier function after chemotherapy is detrimental to the cancer patient, as it can result in various pathologies, including inflammation, ulceration, pain, nausea, diarrhea, sepsis, and multiple organ dysfunction and failure (Keefe et al., 2004). In addition to reducing the quality-of-life of these patients, CIM often leads to dose-reduction and subsequent decrease of anticancer effect, sometimes even resulting in death.

Despite substantial improvements in cancer treatments and a continuous decline in its incidence in the population, CIM remains a significant and common clinical challenge in many cancer patients (Henley et al., 2020). Consequently, there is a strong consensus that effective strategies are needed for the prevention and treatment of CIM, including new monotherapies and drug combinations (Scarpignato and Bjarnason, 2019; Dahlgren et al., 2020). Crucial to this endeavor is a better understanding of the pathophysiological factors and adaptive processes involved in the regulation and repair of an injured intestinal epithelium (Odenwald and Turner, 2017). For instance, glucagon-like peptide-1 (GLP-1) and -2 (GLP-2) have a central role in the adaptive recovery response in the small intestine (Hytting-Andreasen et al., 2018; Billeschou et al., 2021). Our contribution to this field is the development of relevant in vivo models that provide us with a conceptual and rational approach to treat CIM, coupled with a close and rapid collaboration with clinical partners. This review presents an overview of the functions and physiology of the healthy intestinal barrier followed by a summary of the pathophysiological mechanisms involved in the development of CIM. A literature search was performed using the Pub-Med without any time limit for article inclusion, using the following search words: chemotherapeutics-induced intestinal mucositis, intestinal mucositis, chemotherapeutics gut toxicity, chemotherapeutics gastrointestinal side-effects. Finally, we highlight some of the available pharmacological and microbial interventions (prophylactic, acute, and recovery) that have shown clinical potential, with an emphasis on combination treatments. The main objective of this review was to scrutinize and analyze CIM and to discuss and propose a few novel medical strategies.

\section{ANATOMY AND PHYSIOLOGICAL FUNCTIONS OF THE GASTROINTESTINAL TRACT}

\section{Anatomy}

The morphology of the intestinal barrier varies between regions, but it has a common histology composed of four distinct layers: the mucosa (epithelium, lamina propria, and muscularis mucosae); the submucosa; the muscle layer (circular and longitudinal muscle, and the in-between myenteric nerve plexus); and the serosa. The first barrier between lumen and blood is the mucosal epithelium, which is comprised of columnar IEC covered by a protective mucus layer (Johansson et al., 2013). The IECs are sealed together at the apical surface by tight junction proteins, which form the primary physical barrier to small hydrophilic molecules (approximately less than $250 \mathrm{Da}$ ) across the IEC (Fagerholm et al., 1999; Van Itallie and Anderson, 2004). These structurally and biochemically differentiated paracellular regions primarily include tight junctions and anchoring junctions. Tight junctions hold the cells together and form a near leak-proof intercellular seal by fusing adjacent cell membranes, while the anchoring junctions provide essential adhesive and mechanical properties (Andrade et al., 2015). In the small intestine, the mucosa is built up by fingerlike villous protrusions that increase the surface area by a factor of about 6 compared to a smooth tube (Helander and Fändriks, 2014). The lamina propria below the IEC layer contains blood vessels, nerve fibers, lymphatic vascular systems, smooth muscle that regulates blood flow and villi movement, and immune cells such as neutrophils, T-regulatory cells, macrophages, and mast cells (about 1 to 10 immune cells per IEC in the epithelium) (Mowat and Agace, 2014). It also contains the most recently identified cells of the innate immune system, the innate lymphoid cells, where they are involved in and coordinate tissue homeostasis during for instance infection, inflammation and cancer by promoting remodeling, healing and repair (Artis and Spits, 2015). The submucosa contains connective tissue with major blood and lymphatic vessels (Bernier-Latmani and Petrova, 2017). The muscle layer contains the submucous plexus, glial cells, cells of Cajal, and circular and longitudinal muscles that control GI movement, while the serosa is mainly composed of connective tissue that supports the GI tract in the abdominal cavity.

The neurons and their nerve fibers in the GI tract are jointly called the enteric nervous system, which is involved in regulation of peristalsis, secretion, digestion and absorption (Furness, 2012). Intestinal microbiota is also sometimes regarded as a part of the GI system, where it is part of a harmonious ecosystem together with the host. It has recently been estimated that the human body hosts up to $10^{13}$ bacteria, and therefore, about $50 \%$ of the cells in our body are non-eukaryotic (Sender et al., 2016). Luminal bacteria and mucosal immune cells show region-related distribution with a higher abundance of bacteria in the distal regions and a more varied immune cell distribution (Mowat and Agace, 2014; Donaldson et al., 2016). Together, they have synergetic roles in maintaining intestinal homeostasis and also the dysregulation associated with intestinal inflammation (Holzapfel et al., 1998).

\section{Physiological Functions}

The primary physiological functions of the GI tract are to digest food and to absorb water and nutrients from the intestines and regulate metabolism. In parallel it acts as a dynamic barrier preventing absorption of peptides/proteins/xenobiotics/toxins and translocation of microbes and viruses into the underlying tissue, organs, and systemic circulation (Marchiando et al., 2010). The intestinal mucosa is thus a selective barrier with the complex 


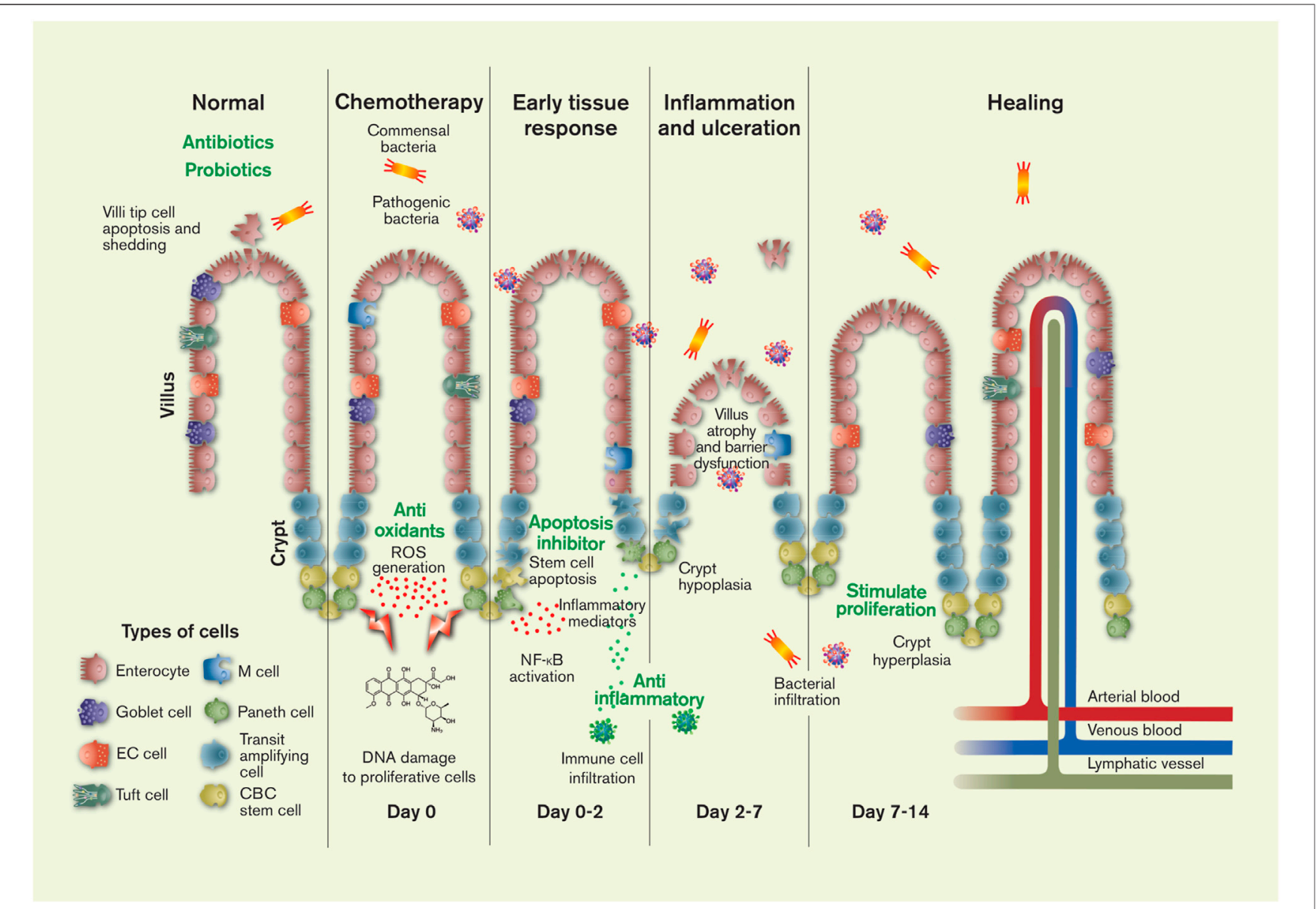

FIGURE 1 | The pathology and timeline of chemotherapeutics-induced intestinal mucositis is primarily related to the effect of cytostatics on stem cells in the proliferation zone of the crypts: crypt base columnar (CBC) stem cells and transit amplifying daughter stem cells. Injury to the DNA of these cells causes apoptosis and initiates of a range of local tissue responses. These include generation of reactive oxygen species (ROS) and inflammation mediators, leading to further injury, inflammation, ulceration, villus and crypt atrophy, and the interstitial infiltration of luminal bacteria (commensal and pathogenic) and immune cells. After about 2 weeks the histology of the intestine is restored in humans ( 1 week in rodents). The green texts show potential targets for CIM intervention. The figure also shows the six different mature cell types of the intestines, the villi protrusions present in the small intestine, and the lymphatic, venous and arterial vessels. Artwork by Febe Jacobsson. $\mathrm{EC}=$ enterochromaffin.

task of simultaneously balancing optimal protection against the harsh biochemical and mechanical luminal environment while allowing efficient nutrient absorption (Dahlgren et al., 2014; Ahluwalia et al., 2017). The GI tract is also a highly specialized chemosensory organ, with the capacity to sense nutrients via various receptors from the luminal side to optimize and coordinate digestion, metabolism, and absorption of the diet following ingestion of food and fluids, as well as in the defense response to pathogens present in the lumen. The ingestion of a meal starts neural and hormonal signaling from the GI tract in response to gastric distension and the chemical presence of nutrients in the GI lumen (Steinert et al., 2016).

The permeability and health of the intestinal barrier is strictly regulated by a range of neuroendocrine processes, hormones, and luminal stimuli that jointly aim at upholding homeostasis in conjunction with the different IEC (Chelakkot et al., 2018). The intestinal epithelium contains six mature cell types with distinctly different functions: two absorptive IECs (enterocytes and M cells) and four secretory IECs (goblet cells, enteroendocrine cells, Paneth cells, and tuft cells) (Figure 1). The function of the enterocytes is to absorb nutrients, water and ions; they constitute about $80 \%$ of the intestinal cells (Gehart and Clevers, 2019). The M-cells are part of the gut-associated lymphoid tissue-the largest immunological tissue in the body-where they allow some uptake of luminal bacteria, thereby triggering or preventing an immunological response depending on the antigen (Ohno, 2016). Thus, the microflora in the intestinal lumen is essential for normal intestinal function and plays an important dynamic role in health and disease progression. Two of the secretory cells primarily secrete into the lumen, where goblet cells secrete protective mucus and the Paneth cells anti-microbial compounds. The other two secretory 



FIGURE 2 | Illustration of the rapid recovery (about $60 \mathrm{~min}$ ) of the rat small intestinal blood-to-lumen 51 Cr-EDTA clearance following local luminal exposure to saline (white area) and two mucosal irritants (grey area): (A) ethanol 30 min (Sommansson et al., 2013b) and (B) sodium dodecyl sulfate (SDS, anionic surfactant) 15 min (Dahlgren et al., 2018b).

cells secrete primarily into the interstitium as a response to luminal stimuli. The tuft cells are involved in the defense against parasitic infections. The enteroendocrine cells secrete more than 30 different peptide hormones involved in a range of GI and systemic functions, which makes the gut the largest endocrine system in the body (Gribble and Reimann, 2016).

\section{PATHOPHYSIOLOGY OF CHEMOTHERAPEUTICS-INDUCED MUCOSITIS}

\section{Normal Injury Response and Mucosal Proliferation}

The continuous, everyday mechanical and/or chemical injury to the outer villi sections and epithelium in the lumen is repaired within minutes to hours. This is exemplified in Figure 2, which shows the changes in intestinal permeability of the clinical mucosal integrity marker, 51Cr-EDTA (Dahlgren et al., 2017), following luminal exposure of the rat small intestine to ethanol and sodium dodecyl sulfate. This acute repair process reestablishes the tight junctions thereby restoring the intestinal barrier function and avoiding translocation of harmful luminal bacteria and macromolecules into the underlying mucosa. The repair is also crucial for re-establishing other cellular functions, including water regulation and nutrient absorption. The intestinal integrity and local tissue homeostasis is initially upheld by restitution. This is a process in which IEC at the tip of the villi, and injured IEC, undergo different types of cell death, such as anoikis, apoptosis, necroptosis and pyroptosis (Patankar and Becker, 2020). Dead cells slough off, while neighbouring epithelial cells migrate to close the gap. In healthy intestine, this process occurs without any clinically relevant loss of barrier function (Marchiando et al., 2011; Gehart and Clevers, 2019).

A prerequisite for restitution is a continuous renewal of cells from the lower layer of the epithelium. This renewal takes place in the crypts of Lieberkühn, the proliferative region of the intestinal mucosa. These crypts are positioned at the base of the villus protrusions in the small intestine, and directly on the flat surface of the colon. The crypts are invaginations in the epithelium that are protected from mechanical and chemical injury and pathogens, from the luminal side. Each crypt is thought to contain about 15 crypt base columnar stem cells located at cell positions 1-3 (cp1-cp3) from the bottom, wedged between the Paneth cells that secrete anti-microbial compounds. (Potten et al., 2009) These stem cells divide infinitely once every $24 \mathrm{~h}$ to initially form a transit population of rapidly dividing progeny cells. These in turn each divide about six times in total, adding up to about 300 new cells per day per crypt (Gehart and Clevers, 2019). As there are about $4-10$ crypts per villus depending on small intestinal region (Keefe, 1998), about 1200-3000 cells are shed every day for each villus.

Generation 1 transit population cells at cell position 4 from the bottom (called +4 cell or cp4) to 3 (cp6) divide rapidly and are uncommitted, whereas the transit population cells are committed from generation 4 (cp7) (Duncan and Grant, 2003; Gehart and Clevers, 2019). These committed cells differentiate into the six distinct intestinal cell types, as discussed previously. With the exception of the Paneth cells that travel to the bottom of the crypts, these post-mitotic cells are pushed outward by the constant renewal in the crypts, and they travel along the villus to finally undergo apoptosis and shedding into the lumen at the tip (Gehart and Clevers, 2019). This way only mature cell types face the harsh environment of the lumen, and only for a relative short time; the epithelial surface of the intestine is renewed about every 3-4 days (Darwich et al., 2014). The sources and essential signalling pathways-and their complex interplay in the determination of cell proliferation and differentiation in the intestinal crypts-have been elegantly illustrated by Gehart and Clevers (Gehart and Clevers, 2019). In principal these processes are balanced by two opposing top-to-bottom crypt gradients. In the one gradient, WNT secreted by the Paneth cells and mesenchymal cells in the crypt bottom maintain stem cell function. In the other gradient, bone morphogenetic proteins-secreted by mesenchymal cells higher up in the crypts-counteract the effect of WNT to induce cell maturation. 
Wnt signaling is a highly conserved pathway that plays principal regulatory roles in many developmental and biological processes. Besides its crucial role in tissue homeostasis, Wnt signaling is also found to be activated aberrantly in many human diseases, including cancers and metabolic disorders (Novellasdemunt et al., 2015).

\section{Mechanisms for Chemotherapeutics-Induced Mucositis}

The DNA of crypt stem cells is well protected from the luminal environment. Fluid flows steadily outwards and interspaced Paneth cells secrete antimicrobial products, making crypts essentially a sterile environment (Nylander and Sjöblom, 2007; Wehkamp and Stange, 2020). However, injury to the DNA in stem cells may arise from events like radiation and cytostatics, causing the cells to go into apoptosis as well as other types of cell death. Still, even when the stem cell pool is completely wiped out it is replenished within a few days. This is possible primarily because initial generations of progeny cells may revert back to the parent stem cell type in the crypt when these are lost. However, others claim that also more committed cells may de-differentiate and repopulate the crypt stem cells upon injury (Buczacki et al., 2013; Yan et al., 2017).

One key issue with chemotherapy is what happens when the cell mitosis and amplification processes in the cryptal stem cells and progenitor cells are compromised by apoptosis. The degree of apoptosis and the local cryptal variations differ depending what cytostatic drug that is used (Ijiri and Potten, 1983). Regardless, normal cell maturation and regeneration of the epithelium is impaired, which means that the continuous (normal) shedding of apoptotic IECs at the tip of the villi is unaccompanied by adequate cellular renewal. In addition, antineoplastic drugs may also be harmful to non-dividing cell populations in the intestine, potentiating any negative effects of an altered cryptal cell renewal. For example, the cytostatic doxorubicin (DOX) is associated with both production of reactive oxygen species and mitochondrial dysfunction (van der Zanden et al., 2020).

Sonis et al. have proposed a general five-stage model for the development of CIM over time (Figure 1): 1) initiation, 2) signalling activation and primary damage response, 3) amplification of biological pathways, 4) tissue inflammation and ulceration, and 5) healing (Sonis, 2009; Al-Dasooqi et al., 2013). The initiation phase is characterized both by direct DNA injury and the generation of reactive oxygen species. The primary damage response starts within seconds of DNA strand breaks and the reactive oxygen species activate signalling factors such as Wnt/ $\beta$-catenin, p53, caspase-1/3, Bcl-2 and NF- $\mathrm{B}$, and their associated pathways (Bowen et al., 2006; Sukhotnik et al., 2014; Bowen et al., 2019). These effects jointly cause death to the intestinal stem cell population and subsequent breakdown of the intestinal barrier. NF- $\kappa B$ is especially well studied in CIM, because it plays a fundamental role in pathogenesis by regulating a range of cytokines (e.g., TNF- $\alpha$, IL-6, IL-1, IL-18, and IL-33), stress responders, cell adhesion molecules, as well as apoptosis in normal cell populations (Ribeiro et al., 2016). Many of these effects leads to signalling amplification, whereby the positive and negative feedback responses of the initial factors affect the local tissue in a complicated biochemical interplay. For instance, NF- $\kappa \mathrm{B}$

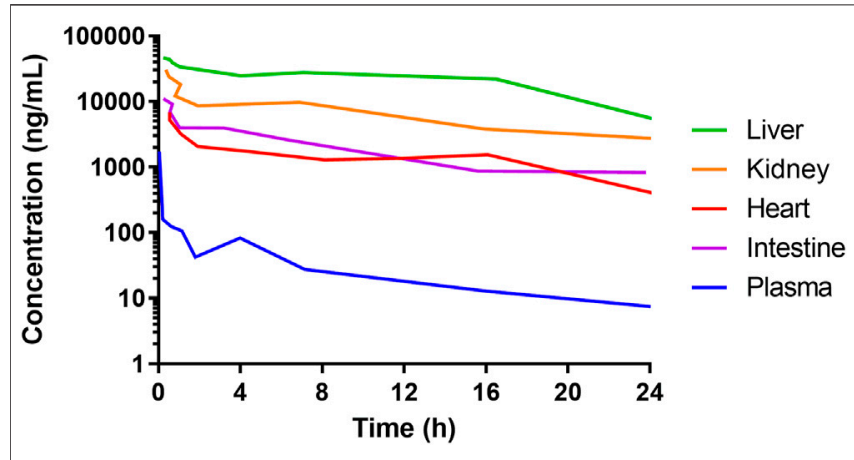

FIGURE 3 | Concentrations of doxorubicin in plasma and liver, heart, kidney, and intestines of mice following $5 \mathrm{mg} / \mathrm{mL}$ intravenous administration of a solution. Data from Luo et al. (2017). The high concentration of doxorubicin in all the organs shows that the side-effects of many anti-cancer drugs are not ubiquitously dose-dependent. Rather, they are associated with the tissue-specific cell proliferation rate. This is why cancer tissue and healthy intestinal tissue are typically heavily affected.

activates TNF- $\alpha$ release, which in turn activates more NF- $\kappa$ B. The overall effect of the overwhelming biochemical response is mucosal inflammation and ulceration, characterized by an ablation of the epithelial villi, a disruption of IEC adhesion, and an increased translocation of luminal components and immune cells into the lamina propria. This cascade of events leads to even more inflammation. The final stage is the spontaneous healing phase in which normal epithelial proliferation, migration, differentiation and maturation are restored.

The whole alimentary tract is formed from the same structure in the embryo (Stringer et al., 2009), and any effects of chemotherapy should be similar in all regions (oral cavity, stomach, small and large intestine) as the same genes are activated (Yeoh et al., 2007). Nonetheless, there are important physiological and anatomical differences. The mouth and small intestine seem to be most affected by mucositis, and have therefore been the regions most studied (Keefe et al., 2004). The dissimilarity in injury has been attributed to the different regional expression of pro- and anti-apoptotic factors, such as Blc-2, which amplifies apoptosis in the small intestinal crypts (Bowen et al., 2005). Spontaneous apoptosis is 10 times more common in the small intestine than the large intestine, and the small intestine is therefore, not surprisingly, more vulnerable to mucositis induced by chemotherapeutics and radiotherapy (Bowen et al., 2006). The lower apoptosis frequency in the large intestine also contributes to the higher incidence of cancers in the lower compared to the upper intestinal tract.

The time from drug exposure to the epithelial effects varies for different species, doses, administration routes and type of chemotherapeutics, and partly follows species-specific differences in crypt turnover. For instance, after an intravenous dose of DOX, the concentration in the intestine is about 100 times higher than in plasma in animals and humans (Luo et al., 2017; Lee et al., 2020). Although the DOX concentrations in the intestines might be similar as in the liver, kidney, and heart, they cause greater damage to the IECs because these cells have a rapid and extensive proliferation (Figure 3) (Luo et al., 2017). In mouse and rat, the cellular apoptosis 
TABLE 1 | Potential future treatment options and some examples of specific interventions for CIM. Please see the text for a more detailed description of the proposed treatment strategies.

\begin{tabular}{|c|c|c|}
\hline Treatment options & Examples & Mechanisms \\
\hline \multirow[t]{3}{*}{ Microbiota } & Antibiotics & Reduces pathogenic intestinal bacteria and mucosal infections \\
\hline & Dihydrotanshinoneon & Restores normal gut microbiota \\
\hline & Probiotics and fecal microbiota transplantations & Reduces diarrhea, reduce pathogenic bacteria, modulating inflammatory response \\
\hline Anti-oxidants & Amifostine, melatonin & Detoxifies reactive metabolites of chemotherapeutic agents and scavenges free radicals \\
\hline Mucosal barrier regulators & Melatonin & Reduces basal and Gl injury increases in intestinal permeability \\
\hline Anti-inflammatory agents & Misoprostol, COX-2 inhibitors & Reduces inflammatory response and propagation \\
\hline Anti-apoptotic agents & IL-1 receptor antagonist, $\beta$-arrestins & Suppression of crypt cell death \\
\hline Incretins & GLP1 and GLP2 & Stimulate growth, promote healing and inhibits epithelial apoptosis \\
\hline Growth hormones & Keratinocyte growth factor & Stimulates proliferation \\
\hline
\end{tabular}

in the crypts peaks at about 6-24 h after DOX administration (Thakkar and Potten, 1992), whereas the maximum effects of the villi height and crypt depth peaks at about 72-96 h (Dekaney et al., 2009). This is also the same time interval after DOX treatment at which the cellular renewal process is peaking in the crypts (Dekaney et al., 2009). A complete recovery of the mucosa and its function are restored after about one week in mouse and rat. In humans, these processes are similar to the rodent models, but the peak times are different and the overall time to recovery is about twice as long (Keefe et al., 2004).

CIM not only affects the stem cell population. It also has a complex interplay between the many mucosal cell types (e.g., IEC, immune cells, mesenchymal cells) in the different intestinal compartments (e.g., villus, crypts, intra and extracellular, mucus). These cell types and compartments are important in the injury and healing following cytostatics treatment. For instance, germ-free mice experience the same amount of DOX-induced increase in cryptal apoptosis as normal mice, but the overall intestinal mucosal injury is greater in the normal mice (Rigby et al., 2016). Single intraperitoneal injection of methotrexate $(20 \mathrm{mg} / \mathrm{kg})$ to Sprague-Dawley rats (200-250 g) causes severe enterocolitis and death (Mao et al., 1996). However, oral administration of lactobacilli to the treated rats significantly improves their intestinal nutritional status and dynamic barrier function, reduces the number of enteric pathogenic bacteria, and most likely explains the reduction of the bacterial translocation and endotoxemia.

This illustrates the symbiotic interplay between microbiota and the activation of the immune system in maintaining intestinal homeostasis. This is further exemplified by the role of the TLR receptors 2 and 9 that are expressed on a range of intestinal cell types. These receptors recognize bacterial epitopes and determine different responses to commensal and other intestinal bacteria. Mice lacking these receptors display less CIM, most likely as a result of a downregulation of intestinal apoptosis.(Kaczmarek et al., 2012) The extracellular matrix is also important for maintaining tissue morphology and healing. The cancer drug irinotecan is known to affect extracellular matrix protein expression, which contributes to cell cytostasis and apoptosis followed by an increase in collagen deposits partly attributed to changes in the expression of metalloproteinases (Al-Dasooqi et al., 2010; Al-Dasooqi et al., 2011). Furthermore, after cytostatics treatment, it is fundamental for mucosal health that the protective epithelial mucus layer is rebuilt by the mucins. These mucins are involved in cell proliferation, the inhibition of apoptosis, and the overall severity of CIM (Thorpe, 2019).

The multitude of parameters involved in CIM, and our improved understanding of its pathophysiology, give rise to many possible targets for various treatment strategies. Below and in Table 1 follows a summary of some interesting past and recent studies and potential targets.

\section{POSSIBLE TREATMENT OPTIONS FOR CIM}

There is an unmet need to identify and develop efficient drug treatments for GI toxicities caused by chemotherapeutics (Stringer et al., 2009; Sougiannis et al., 2021). The overall aims of any intervention are to reduce the GI related symptoms experienced by cancer patients-this would relieve suffering, enable dose escalation, or avoid dose de-escalation. Interventions can include prophylactic treatments such as probiotics and antibiotics to prepare the GI tract. They may also include anti-oxidants, anti-inflammatory drugs, and apoptosis inhibitors during cytostatics treatment to alleviate some of the immediate toxicities and associated effects. Lastly, treatments such as incretins and growth hormones can be used after cytostatic dosing to benefit the mucosal adaptation and proliferation processes after injury. This section discusses some promising interventions that can be deployed in each of the three stages. Finally, we highlight the usefulness of combining treatment options to tackle CIM from multiple angles.

\section{Microbial and Anti-microbial Treatments}

The microbiota can have both detrimental and supportive effects on GI homeostasis and health (Benno et al., 2019). This also holds true for CIM, where luminal bacteria are involved in the regulation of intestinal barrier functions, maintenance of selective intestinal permeability, inflammation and innate immune response, repair mechanisms, cell apoptosis, and oxidative stress (Prisciandaro et al., 2011). The direct or indirect effects of cytostatics on gut microflora dysbiosis also impact the clinical manifestations of CIM, where they contribute to the development of bacteremia and diarrhea. Accordingly, there is an abundance of preclinical CIM rodent models that have 
reported positive effects of antibiotics (Hamouda et al., 2017), fecal transplantations (Chang et al., 2020), and probiotics (Yeung et al., 2015; Quaresma et al., 2020). In a mouse model, CIM toxicity has been reduced with dihydrotanshinoneon (a liposoluble plant extract) that restores normal gut microbiota (Wang et al., 2020). In patients undergoing GI surgery, a changed microbial intestinal flora in combination with an altered barrier function may progress to an enhanced inflammatory response. Here probiotics may reduce pathogenic bacteria (Jeppsson et al., 2011). Still, in spite of the vast literature supporting the use of treatments directly or indirectly targeting the luminal microbiota, treatments for CIM that alter the GI microbiome have largely failed in the clinic (Touchefeu et al., 2014), Consequently, there is a need to improve and establish the most suitable composition of type of probiotic bacteria, and its dose and length of treatment. Of special interest is the possibility of combining interventions, such as pre-treatment with antibiotics that target bacterial populations with noxious membrane effects, and beneficial probiotic/fecal microbiota transplantations.

\section{Anti-Oxidants and Mucosal Barrier Regulators}

Amifostine is a phosphorylated aminothiol prodrug, which is rapidly hydrolysed in vivo by alkaline phosphatase to the active cytoprotective thiol metabolite, WR-1065. This metabolite has a terminal half-life of $90 \mathrm{~min}$ (Ranganathan et al., 2018). Intracellularly WR-1065 detoxifies reactive metabolites of chemotherapeutic agents and scavenges free radicals (Bensadoun et al., 2006); it may also accelerate DNA repair and inhibit apoptosis. As such, intravenous administration of WR-1065 may protect intestinal epithelium and connective tissue from various anti-tumor treatments (Grdina et al., 2000). It reduces DOX-induced CIM in rats (Jaćević et al., 2018) and methotrexate-induced CIM in mice, an effect that is potentiated by co-administration of calcium folinate (Chen et al., 2013) The FDA indication for amifostine refers to xerostomia prophylaxis in post-operative head-neck-cancer patients treated with radiotherapy (Antonadou et al., 2002); however, the data are conflicting about its value in oral CIM prevention (Nicolatou-Galitis et al., 2013). Unfortunately, significant side-effects (mainly nausea and hypotension) limit its clinical use.

Melatonin, a serotonin derivative, is a hormone that controls the sleep-wake cycle and is primarily released by the pineal gland at night (Auld et al., 2017). Melatonin is also synthesized and released by the enterochromaffin cells in the intestine, where it binds to the melatonin membrane receptors MT1 and MT2, and to the cytosolic MT3 receptor (Soták et al., 2006; Söderquist et al., 2015). It also scavenges free radicals (Hardeland and PandiPerumal, 2005). In rats and mice, melatonin reduces basal intestinal permeability through an inhibitory nicotinic receptor-mediated neural pathway (Sommansson et al., 2013a). This mitigates ethanol-, chemical-, and radiation-induced intestinal damage (Monobe et al., 2005; Sommansson et al., 2013a; Chamanara et al., 2019), as well as methotrexateinduced oxidative stress and injury (Kolli et al., 2013). Clinical trials with melatonin also report positive effects in irritable bowel syndrome and inflammatory bowel disease (Rakhimova, 2010; Siah et al., 2014). In summary, melatonin has a potent effect on mitigating mucosal injury. It should therefore be investigated for limiting CIM, in particular in synergism with other treatments. For example, melatonin dosed with misoprostol abolishes unselective surfactant-induced intestinal injury in rat (Dahlgren et al., 2020).

\section{Anti-Inflammatory and Anti-apoptotic Agents}

Pro-inflammatory cytokines, such as IL-1, are involved in the progression of CIM (Kanarek et al., 2014), and their natural antagonists are released upon intestinal injury (Daig et al., 2000). As such, the IL-1 receptor antagonist is repeatedly shown to reduce 5-fluorouracil-induced CIM in mice ( $\mathrm{Wu}$ et al., 2010; Wu et al., 2011). These effects are attributed to reduced crypt cell death by suppression of p53-dependent apoptosis caused by cytotoxic treatments (Wang et al., 2015). Other mediators in cell apoptosis are $\beta$-arrestins that suppress p53 levels (Hara et al., 2011). For example, mice deficient in $\beta$-arrestin1 experience increased cell death and injury following cytostatics (Zhan et al., 2016). Other ways to reduce caspase-3 activated cells and apoptosis in mice after 5fluorouracil-induced mucositis include: a serotonin-receptor antagonist (Yasuda et al., 2013); andrographolide (an herbal extract) (Xiang et al., 2020); and armillariella oral solution (a fungus extract) (Wenqin et al., 2019). These preclinical studies show the potential in targeting cell apoptosis pathways to limit mucosal manifestations and complications in CIM.

The prostaglandin $\mathrm{E}_{1}$ analogue, misoprostol, is an agonist of $\mathrm{G}$ protein-coupled prostaglandin E receptors 1-4 that are involved in epithelial homeostasis and protect against intestinal mucosal damage (Abramovitz et al., 2000). Misoprostol protects by regulating gastric acid and mucus secretion, pro-inflammatory cytokine production, and by activating adaptive cell survival pathways through selective gene repression and splicing (Davies et al., 2001; Field et al., 2018). It is therefore used for the prevention of nonsteroidal anti-inflammatory drug-induced mucosal erosions and ulcers (Graham et al., 1988; Sugimoto and Narumiya, 2007). It is effective at reducing radiation induced injury in animal models (Hanson et al., 1988; Delaney et al., 1994), but its clinical use for treating radiotherapy-induced intestinal and oral mucositis have generated conflicting results, both positive (Hanson et al., 1995) and negative (Duenas-Gonzalez et al., 1996) outcomes. Still, the abundant clinical and preclinical data supporting its cytoprotective effects for a range of GI inflammation and injury models make it a promising drug for further investigations with CIM.

Cyclooxygenase (COX) 1 and 2 are enzymes involved in the formation of prostanoids, which are involved in numerous physiological processes including inflammation (Dahlgren et al., 2018a). COX-1 is expressed and produced 
constitutively whereas COX-2 production (prostaglandin E2) is induced at sites of inflammation by pro-inflammatory agents (e.g., IL-1, TNF- $\alpha$ ) and transcription factors (e.g., NF- $\mathrm{BB}$ ) (Turini and Dubois, 2002). The involvement of these mediators in the progression of CIM has led several studies to explore the possible contribution of $\mathrm{COX}-2$ to the amplification phase rather than the acute phase of CIM (Sonis et al., 2004). Accordingly, selective COX-2 inhibition is reported to reduce the overall histopathological changes and/ or diarrhoea induced by various cytostatics in rodent models [e.g., 5-fluorouracil (De Miranda et al., 2020) and irinotecan (Javle et al., 2007)]. The same treatments have also been used in the clinics for radiation and chemotherapeutics-induced oral and intestinal mucositis, but with mixed results (Javle et al., 2007; Lalla et al., 2014). Overall, the overlap between effectors in CIM and in inflammatory induction of COX-2 make them a possible adjuvant treatment target.

\section{Incretins and Growth Hormones}

Endogenous glucagon-like peptides GLP-1 and GLP-2 are released by the enteroendocrine L-cells into the lamina propria and circulation following oral nutrient ingestion. They stimulate growth, increase absorption, promote healing, maintain intestinal epithelial integrity, and potentially have anti-inflammatory activity (Drucker et al., 1996; Drucker and Yusta, 2014; Ebbesen et al., 2019; Billeschou et al., 2021). The positive effect of luminal food on epithelial growth is also why enteral feeding should be maintained during chemotherapy (Bengmark and Jeppsson, 1995). Plasma levels of GLP-1 correlate with the systemic inflammation in cancer patients receiving chemotherapy; plasma GLP-2 concentrations are significantly elevated 2-5 days following induction of CIM in rats and mice (Kissow et al., 2012; Hytting-Andreasen et al., 2018; Ebbesen et al., 2019). Besides the enhancement of proliferation, exogenous GLP-2 inhibits epithelial apoptosis (Tsai et al., 1997; Boushey et al., 2001). Other studies show GLP- 1 and 2 to be central in the adaptive recovery response in the small intestine following CIM (Kissow et al., 2013; HyttingAndreasen et al., 2018; Billeschou et al., 2021). Thus, GLP-1 and 2, their analogues (semaglutide/exenatide and teduglutide/glepaglutide), or inhibition of their enzymaticmediated degradation (DPP-IV inhibitors) have great promise for improving mucosal regeneration after CIM, in part by reducing chemotherapy-induced apoptosis (Boushey et al., 2001). GLP-2 analogues also have clinical potential when the integrity or absorptive function of the intestinal mucosa is affected (Salaga et al., 2018).

Another interesting growth factor is the keratinocyte growth factor (KGF), a protein in the fibroblast growth factor family. KGF is a small signalling molecule that binds to fibroblast growth factor receptor $2 \mathrm{~b}$ which is expressed in the intestine (Song et al., 2020). KGF stimulates proliferation and increases the overall weight of the intestine (Housley et al., 1994). It has been evaluated in rodent models of CIM, but effects have been both positive (Farrell et al., 1998) or absent (Gibson et al., 2002). A human recombinant version of KGF, palifermin, is the only approved (oral) drug treatment for CIM today. As an injection drug, it is used for treating severe oral mucositis in patients receiving myeloablative radiochemotherapy (Nasilowska-Adamska et al., 2007). The cytoprotective effects of palifermin could be expanded to include other indications (Vadhan-Raj et al., 2013).

\section{Combination Treatments}

Despite decades of experimental and clinical investigations of CIM, no effective therapeutic interventions are available today for treating it (Ribeiro et al., 2016; Wardill et al., 2019). What treatments that do exist aim at reducing secondary complications to treatment, such as pain and diarrhoea. Consequently, no single treatment to date substantially transforms the clinical management of CIM, despite numerous promising preclinical investigations. This cements the fundamental role of stem cell proliferation in mucosal health and homeostasis, and suggests that its disturbance by chemical agents is so fundamental that no single intervention can readily compensate. Unless any novel breakthrough occurs in this regard, it is our belief that combinations of treatments are necessary to generate any substantial clinical breakthrough in CIM management. A few example of successful additive combinations treatments for alleviating CIM in preclinical models include GLP 1 and 2 (Hytting-Andreasen et al., 2018), troxerutin and celecoxib (De Miranda et al., 2020), amifostine and calcium folinate (Chen et al., 2013). The combinations with the most potential to be successful (high positive ratio of effect/safety) remain to be investigated, validated, and established. An optimal intervention would likely target the pre-treatment phase of CIM with prophylactics (e.g., antibiotics/probiotics), the acute phase with anti-oxidants and anti-inflammatory agents, and the recovery phase, by stimulation of cell proliferation.

\section{CONCLUSIONS}

Gastrointestinal injury and symptoms following chemotherapy in cancer patients remains an unsolved clinical issue. As there are currently no effective treatment options for chemotherapeutics-induced intestinal mucositis, there is no way to help these patients other than by lowering the dose of the cytotoxic drug. However, recent progress in the understanding of the molecular and functional pathology of CIM provides many new potential targets and treatment opportunities. We believe that the best possibility for success is to pursue combination treatments that target different aspects of the complex pathological mechanisms involved in intestinal mucositis.

\section{AUTHOR CONTRIBUTIONS}

Conceptualization: DD, MS, PH, HL; methodology: DD, HL; investigation: $\mathrm{DD}, \mathrm{HL}$; resources: $\mathrm{HL}$; data curation: $\mathrm{DD}$; writing-original draft preparation: DD, HL; writing-review and editing: DD, MS, PH, HL; visualization: DD; funding 
acquisition: HL; All authors have read and agreed to the published version of the manuscript.

\section{FUNDING}

HL is funded through grants obtained from the Swedish Cancer Foundation (Grant No. CAN2018/602) and Swedish

\section{REFERENCES}

Abramovitz, M., Adam, M., Boie, Y., Carrière, M.-C., Denis, D., Godbout, C., et al. (2000). The Utilization of Recombinant Prostanoid Receptors to Determine the Affinities and Selectivities of Prostaglandins and Related Analogs. Biochim. Biophys. Acta (BBA) - Mol. Cell Biol. Lipids 1483, 285-293. doi:10.1016/s13881981(99)00164-x

Ahluwalia, B., Magnusson, M. K., and Öhman, L. (2017). Mucosal Immune System of the Gastrointestinal Tract: Maintaining Balance between the Good and the Bad. Scand. J. Gastroenterol. 52, 1185-1193. doi:10.1080/00365521.2017. 1349173

Al-Dasooqi, N., Bowen, J. M., Gibson, R. J., Logan, R. M., Stringer, A. M., and Keefe, D. M. (2011). Irinotecan-induced Alterations in Intestinal Cell Kinetics and Extracellular Matrix Component Expression in the Dark Agouti Rat. Int. J. Exp. Pathol. 92, 357-365. doi:10.1111/j.1365-2613.2011.00771.x

Al-Dasooqi, N., Gibson, R. J., Bowen, J. M., Logan, R. M., Stringer, A. M., and Keefe, D. M. (2010). Matrix Metalloproteinases Are Possible Mediators for the Development of Alimentary Tract Mucositis in the Dark agouti Rat. Exp. Biol. Med. (Maywood) 235, 1244-1256. doi:10.1258/ebm.2010.010082

Al-Dasooqi, N., Sonis, S. T., Sonis, S. T., Bowen, J. M., Bateman, E., Blijlevens, N., et al. (2013). Emerging Evidence on the Pathobiology of Mucositis. Support Care Cancer 21, 2075-2083. doi:10.1007/s00520-013-1810-y

Andrade, M. E. R., Araújo, R. S., De Barros, P. A. V., Soares, A. D. N., Abrantes, F. A., Generoso, S. d. V., et al. (2015). The Role of Immunomodulators on Intestinal Barrier Homeostasis in Experimental Models. Clin. Nutr. 34, 1080-1087. doi:10.1016/j.clnu.2015.01.012

Antonadou, D., Pepelassi, M., Synodinou, M., Puglisi, M., and Throuvalas, N. (2002). Prophylactic Use of Amifostine to Prevent RadiochemotherapyInduced Mucositis and Xerostomia in Head-and-Neck Cancer. Int. J. Radiat. Oncol. Biol. Phys. 52, 739-747. doi:10.1016/s0360-3016(01)02683-9

Artis, D., and Spits, H. (2015). The Biology of Innate Lymphoid Cells. Nature 517, 293-301. doi:10.1038/nature14189

Auld, F., Maschauer, E. L., Morrison, I., Skene, D. J., and Riha, R. L. (2017). Evidence for the Efficacy of Melatonin in the Treatment of Primary Adult Sleep Disorders. Sleep Med. Rev. 34, 10-22. doi:10.1016/j.smrv.2016.06.005

Bengmark, S., and Jeppsson, B. (1995). Gastrointestinal Surface Protection and Mucosa Reconditioning. J. Parenter. Enteral Nutr. 19, 410-415. doi:10.1177/ 0148607195019005410

Benno, P., Norin, E., Midtvedt, T., and Hellström, P. M. (2019). Therapeutic Potential of an Anaerobic Cultured Human Intestinal Microbiota, ACHIM, for Treatment of IBS. Best Pract. Res. Clin. Gastroenterol. 40-41, 101607. doi:10. 1016/j.bpg.2019.03.003

Bensadoun, R.-J., Schubert, M. M., Lalla, R. V., and Keefe, D. (2006). Amifostine in the Management of Radiation-Induced and Chemo-Induced Mucositis. Support Care Cancer 14, 566-572. doi:10.1007/s00520-006-0047-4

Bernier-Latmani, J., and Petrova, T. V. (2017). Intestinal Lymphatic Vasculature: Structure, Mechanisms and Functions. Nat. Rev. Gastroenterol. Hepatol. 14, 510-526. doi:10.1038/nrgastro.2017.79

Billeschou, A., Hunt, J. E., Ghimire, A., Holst, J. J., and Kissow, H. (2021). Intestinal Adaptation upon Chemotherapy-Induced Intestinal Injury in Mice Depends on GLP-2 Receptor Activation. Biomedicines 9, 46. doi:10.3390/ biomedicines 9010046

Boushey, R. P., Yusta, B., and Drucker, D. J. (2001). Glucagon-like Peptide (GLP)-2 Reduces Chemotherapy-Associated Mortality and Enhances Cell Survival in Cells Expressing a Transfected GLP-2 Receptor. Cancer Res. 61, 687-693.
Research Council (Grant Nos. 2018-03301 and 202002367).

\section{ACKNOWLEDGMENTS}

We thank Febe Jacobsson for her contribution to the artwork.

Bowen, J., Al-Dasooqi, N., Al-Dasooqi, N., Bossi, P., Wardill, H., Van Sebille, Y., et al. (2019). The Pathogenesis of Mucositis: Updated Perspectives and Emerging Targets. Support Care Cancer 27, 4023-4033. doi:10.1007/s00520019-04893-z

Bowen, J. M., Gibson, R. J., Cummins, A. G., and Keefe, D. M. K. (2006). Intestinal Mucositis: the Role of the Bcl-2 Family, P53 and Caspases in ChemotherapyInduced Damage. Support Care Cancer 14, 713-731. doi:10.1007/s00520-0050004-7

Bowen, J. M., Gibson, R. J., Keefe, D. M., and Cummins, A. G. (2005). Cytotoxic Chemotherapy Upregulates Pro-poptotic Bax and Bak in the Small Intestine of Rats and Humans. Pathology 37, 56-62. doi:10.1080/00313020400023461

Buczacki, S. J. A., Zecchini, H. I., Nicholson, A. M., Russell, R., Vermeulen, L., Kemp, R., et al. (2013). Intestinal Label-Retaining Cells Are Secretory Precursors Expressing Lgr5. Nature 495, 65-69. doi:10.1038/nature11965

Chamanara, M., Rashidian, A., Mehr, S. E., Dehpour, A.-R., Shirkohi, R., Akbarian, R., et al. (2019). Melatonin Ameliorates TNBS-Induced Colitis in Rats through the Melatonin Receptors: Involvement of TLR4/MyD88/NF- $\kappa B$ Signalling Pathway. Inflammopharmacol 27, 361-371. doi:10.1007/s10787-018-0523-8

Chang, C.-W., Lee, H.-C., Li, L.-H., Chiang Chiau, J.-S., Wang, T.-E., Chuang, W.H., et al. (2020). Fecal Microbiota Transplantation Prevents Intestinal Injury, Upregulation of Toll-like Receptors, and 5-Fluorouracil/oxaliplatin-Induced Toxicity in Colorectal Cancer. Int. J. Mol. Sci. 21, 386. doi:10.3390/ ijms 21020386

Chelakkot, C., Ghim, J., and Ryu, S. H. (2018). Mechanisms Regulating Intestinal Barrier Integrity and its Pathological Implications. Exp. Mol. Med. 50, 1-9. doi:10.1038/s12276-018-0126-x

Chen, C., Tian, L., Zhang, M., Sun, Q., Zhang, X., Li, X., et al. (2013). Protective Effect of Amifostine on High-Dose Methotrexate-Induced Small Intestinal Mucositis in Mice. Dig. Dis. Sci. 58, 3134-3143. doi:10.1007/s10620-0132826-3

Dahlgren, D., Cano-Cebrián, M.-J., Hellström, P. M., Wanders, A., Sjöblom, M., and Lennernäs, H. (2020). Prevention of Rat Intestinal Injury with a Drug Combination of Melatonin and Misoprostol. Int. J. Mol. Sci. 21, 6771. doi:10. 3390/ijms21186771

Dahlgren, D., Roos, C., Lundqvist, A., Tannergren, C., Langguth, P., Sjöblom, M., et al. (2017). Preclinical Effect of Absorption Modifying Excipients on Rat Intestinal Transport of Model Compounds and the Mucosal Barrier Marker51Cr-EDTA. Mol. Pharmaceutics 14, 4243-4251. doi:10.1021/acs. molpharmaceut.7b00353

Dahlgren, D., Roos, C., Lundqvist, A., Tannergren, C., Sjöblom, M., Sjögren, E., et al. (2018a). Effect of Absorption-Modifying Excipients, Hypotonicity, and Enteric Neural Activity in an In Vivo Model for Small Intestinal Transport. Int. J. Pharmaceutics 549, 239-248. doi:10.1016/j.ijpharm.2018.07.057

Dahlgren, D., Roos, C., Lundqvist, A., Tannergren, C., Sjöblom, M., Sjögren, E., et al. (2018b). Time-dependent Effects on Small Intestinal Transport by Absorption-Modifying Excipients. Eur. J. Pharmaceutics Biopharmaceutics 132, 19-28. doi:10.1016/j.ejpb.2018.09.001

Dahlgren, D., Roos, C., Sjögren, E., and Lennernäs, H. (2014). Direct In Vivo Human Intestinal Permeability (Peff ) Determined with Different Clinical Perfusion and Intubation Methods. J. Pharm. Sci. 104, 2702-2726. doi:10. 1002/jps.24258

Daig, R., Rogler, G., Aschenbrenner, E., Vogl, D., Falk, W., Gross, V., et al. (2000). Human Intestinal Epithelial Cells Secrete Interleukin-1 Receptor Antagonist and Interleukin-8 but Not Interleukin-1 or Interleukin-6. Gut 46, 350-358. doi:10.1136/gut.46.3.350

Darwich, A. S., Aslam, U., Ashcroft, D. M., and Rostami-Hodjegan, A. (2014). Meta-analysis of the Turnover of Intestinal Epithelia in Preclinical Animal 
Species and Humans. Drug Metab. Dispos 42, 2016-2022. doi:10.1124/dmd.114. 058404

Davies, N. M., Longstreth, J., and Jamali, F. (2001). Misoprostol Therapeutics Revisited. Pharmacotherapy 21, 60-73. doi:10.1592/phco.21.1.60.34442

De Miranda, J. A. L., Martins, C. d. S., Fideles, L. d. S., Barbosa, M. L. L., Barreto, J. E. F., Pimenta, H. B., et al. (2020). Troxerutin Prevents 5 -fluorouracil Induced Morphological Changes in the Intestinal Mucosa: Role of Cyclooxygenase-2 Pathway. Pharmaceuticals 13, 10. doi:10.3390/ph13010010

Dekaney, C. M., Gulati, A. S., Garrison, A. P., Helmrath, M. A., and Henning, S. J. (2009). Regeneration of Intestinal Stem/progenitor Cells Following Doxorubicin Treatment of Mice. Am. J. Physiology-Gastrointestinal Liver Physiol. 297, G461-G470. doi:10.1152/ajpgi.90446.2008

Delaney, J. P., Bonsack, M. E., and Felemovicius, I. (1994). Misoprostol in the Intestinal Lumen Protects against Radiation Injury of the Mucosa of the Small Bowel. Radiat. Res. 137, 405-409. doi:10.2307/3578717

Donaldson, G. P., Lee, S. M., and Mazmanian, S. K. (2016). Gut Biogeography of the Bacterial Microbiota. Nat. Rev. Microbiol. 14, 20-32. doi:10.1038/ nrmicro3552

Drucker, D. J., Erlich, P., Asa, S. L., and Brubaker, P. L. (1996). Induction of Intestinal Epithelial Proliferation by Glucagon-like Peptide 2. Proc. Natl. Acad. Sci. 93, 7911-7916. doi:10.1073/pnas.93.15.7911

Drucker, D. J., and Yusta, B. (2014). Physiology and Pharmacology of the Enteroendocrine Hormone Glucagon-like Peptide-2. Annu. Rev. Physiol. 76, 561-583. doi:10.1146/annurev-physiol-021113-170317

Duenas-Gonzalez, A., Sobrevilla-Calvo, P., Frias-Mendivil, M., Gallardo-Rincon, D., Lara-Medina, F., Aguilar-Ponce, L., et al. (1996). Misoprostol Prophylaxis for High-Dose Chemotherapy-Induced Mucositis: a Randomized Double-Blind Study. Bone Marrow Transpl. 17, 809-812.

Duncan, M., and Grant, G. (2003). Oral and Intestinal Mucositis - Causes and Possible Treatments. Aliment. Pharmacol. Ther. 18, 853-874. doi:10.1046/j. 1365-2036.2003.01784.x

Ebbesen, M. S., Kissow, H., Hartmann, B., Grell, K., Gørløv, J. S., Kielsen, K., et al. (2019). Glucagon-like Peptide-1 Is a Marker of Systemic Inflammation in Patients Treated with High-Dose Chemotherapy and Autologous Stem Cell Transplantation. Biol. Blood Marrow Transplant 25, 1085-1091. doi:10.1016/j. bbmt.2019.01.036

Fagerholm, U., Nilsson, D., Knutson, L., and Lennernäs, H. (1999). Jejunal Permeability in Humans In Vivo and Rats In Situ : Investigation of Molecular Size Selectivity and Solvent Drag. Acta Physiol. Scand. 165, 315-324. doi:10.1046/j.1365-201x.1999.00510.x

Farrell, C. L., Bready, J. V., Rex, K. L., Chen, J. N., Dipalma, C. R., Whitcomb, K. L., et al. (1998). Keratinocyte Growth Factor Protects Mice from Chemotherapy and Radiation-Induced Gastrointestinal Injury and Mortality. Cancer Res. 58, 933-939.

Field, J. T., Martens, M. D., Mughal, W., Hai, Y., Chapman, D., Hatch, G. M., et al. (2018). Misoprostol Regulates Bnip3 Repression and Alternative Splicing to Control Cellular Calcium Homeostasis during Hypoxic Stress. Cell Death Discov. 4, 1-20. doi:10.1038/s41420-018-0104-Z

Furness, J. B. (2012). The Enteric Nervous System and Neurogastroenterology. Nat. Rev. Gastroenterol. Hepatol. 9, 286-294. doi:10.1038/nrgastro.2012.32

Gehart, H., and Clevers, H. (2019). Tales from the Crypt: New Insights into Intestinal Stem Cells. Nat. Rev. Gastroenterol. Hepatol. 16, 19-34. doi:10.1038/ s41575-018-0081-y

Gibson, R., Keefe, D., Clarke, J., Regester, G., Thompson, F., Goland, G., et al. (2002). The Effect of Keratinocyte Growth Factor on Tumour Growth and Small Intestinal Mucositis after Chemotherapy in the Rat with Breast Cancer. Cancer Chemother. Pharmacol. 50, 53-58. doi:10.1007/s00280-002-0460-4

Graham, D., Agrawal, N., and Roth, S. (1988). Prevention of NSAID-Induced Gastric Ulcer with Misoprostol: Multicentre, Double-Blind, Placebo-Controlled Trial. The Lancet 332, 1277-1280. doi:10.1016/s0140-6736(88)92892-9

Grdina, D. J., Kataoka, Y., and Murley, J. S. (2000). Amifostine: Mechanisms of Action Underlying Cytoprotection and Chemoprevention. Drug Metab. Drug interactions 16, 237-279. doi:10.1515/dmdi.2000.16.4.237

Gribble, F. M., and Reimann, F. (2016). Enteroendocrine Cells: Chemosensors in the Intestinal Epithelium. Annu. Rev. Physiol. 78, 277-299. doi:10.1146/ annurev-physiol-021115-105439

Hamouda, N., Sano, T., Oikawa, Y., Ozaki, T., Shimakawa, M., Matsumoto, K., et al. (2017). Apoptosis, Dysbiosis and Expression of Inflammatory Cytokines Are
Sequential Events in the Development of 5-Fluorouracil-Induced Intestinal Mucositis in Mice. Basic Clin. Pharmacol. Toxicol. 121, 159-168. doi:10.1111/ bcpt.12793

Hanson, W., Houseman, K., Nelson, A., and Collins, P. (1988). Radiation Protection of the Murine Intestine by Misoprostol, a Prostaglandin E1 Analogue, Given Alone or with WR-2721, Is Stereospecific. Prostaglandins Leukot. Essent. Fatty Acids 32, 101-105.

Hanson, W. R., Marks, J. E., Reddy, S. P., Simon, S., Mihalo, W. E., and Tova, Y. (1995). Protection from Radiation-Induced Oral Mucositis by Misoprostol, a Prostaglandin E1 Analog. Am. J. Ther. 2, 850-857. doi:10.1097/00045391199511000-00005

Hara, M. R., Kovacs, J. J., Whalen, E. J., Rajagopal, S., Strachan, R. T., Grant, W., et al. (2011). A Stress Response Pathway Regulates DNA Damage through $\beta 2$ adrenoreceptors and $\beta$-arrestin-1. Nature 477, 349-353. doi:10.1038/ nature 10368

Hardeland, R., and Pandi-Perumal, S. (2005). Melatonin, a Potent Agent in Antioxidative Defense: Actions as a Natural Food Constituent, Gastrointestinal Factor, Drug and Prodrug. Nutr. Metab. 2, 1-15. doi:10.1186/1743-7075-2-22

Helander, H. F., and Fändriks, L. (2014). Surface Area of the Digestive Tract Revisited. Scand. J. Gastroenterol. 49, 681-689. doi:10.3109/00365521.2014. 898326

Henley, S. J., Ward, E. M., Scott, S., Ma, J., Anderson, R. N., Firth, A. U., et al. (2020). Annual Report to the Nation on the Status of Cancer, Part I: National Cancer Statistics. Cancer 126, 2225-2249. doi:10.1002/cncr.32802

Holzapfel, W. H., Haberer, P., Snel, J., Schillinger, U., and Huis in't Veld, J. H. J. (1998). Overview of Gut Flora and Probiotics. Int. J. Food Microbiol. 41, 85-101. doi:10.1016/s0168-1605(98)00044-0

Housley, R. M., Morris, C. F., Boyle, W., Ring, B., Biltz, R., Tarpley, J. E., et al. (1994). Keratinocyte Growth Factor Induces Proliferation of Hepatocytes and Epithelial Cells throughout the Rat Gastrointestinal Tract. J. Clin. Invest. 94, 1764-1777. doi:10.1172/jci117524

Hytting-Andreasen, R., Balk-Møller, E., Hartmann, B., Pedersen, J., Windeløv, J. A., Holst, J. J., et al. (2018). Endogenous Glucagon-like Peptide-1 and 2 Are Essential for Regeneration after Acute Intestinal Injury in Mice. PloS one 13, e0198046. doi:10.1371/journal.pone.0198046

Ijiri, K., and Potten, C. S. (1983). Response of Intestinal Cells of Differing Topographical and Hierarchical Status to Ten Cytotoxic Drugs and Five Sources of Radiation. Br. J. Cancer 47, 175-185. doi:10.1038/bjc.1983.25

Jaćević, V., Dragojević-Simić, V., Tatomirović, Ž., Dobrić, S., Bokonjić, D., Kovačević, A., et al. (2018). The Efficacy of Amifostine against MultipleDose Doxorubicin-Induced Toxicity in Rats. Int. J. Mol. Sci. 19, 2370

Javle, M. M., Cao, S., Durrani, F. A., Pendyala, L., Lawrence, D. D., Smith, P. F., et al. (2007). Celecoxib and Mucosal Protection: Translation from an Animal Model to a Phase I Clinical Trial of Celecoxib, Irinotecan, and 5-fluorouracil. Clin. Cancer Res. 13, 965-971. doi:10.1158/1078-0432.ccr-06-0551

Jeppsson, B., Mangell, P., and Thorlacius, H. (2011). Use of Probiotics as Prophylaxis for Postoperative Infections. Nutrients 3, 604-612. doi:10.3390/ nu3050604

Johansson, M. E. V., Sjövall, H., and Hansson, G. C. (2013). The Gastrointestinal Mucus System in Health and Disease. Nat. Rev. Gastroenterol. Hepatol. 10, 352-361. doi:10.1038/nrgastro.2013.35

Kaczmarek, A., Brinkman, B. M., Heyndrickx, L., Vandenabeele, P., and Krysko, D. V. (2012). Severity of Doxorubicin-Induced Small Intestinal Mucositis Is Regulated by the TLR-2 and TLR-9 Pathways. J. Pathol. 226, 598-608. doi:10.1002/path.3009

Kanarek, N., Grivennikov, S. I., Leshets, M., Lasry, A., Alkalay, I., Horwitz, E., et al. (2014). Critical Role for IL-1 $\beta$ in DNA Damage-Induced Mucositis. Proc. Natl. Acad. Sci. USA 111, E702-E711. doi:10.1073/pnas.1322691111

Keefe, D. M., Gibson, R. J., and Hauer-Jensen, M. (2004). "Gastrointestinal Mucositis," in Seminars in Oncology Nursing (Elsevier), 38-47.

Keefe, D. M. K. (1998). The Effect of Cytotoxic Chemotherapy on the Mucosa of the Small Intestine. University of Adelaide, Depts. of Gastroenterology and Haematology/Oncology. doi:10.1007/978-1-349-26390-5

Kissow, H., Hartmann, B., Holst, J. J., and Poulsen, S. S. (2013). Glucagon-like Peptide-1 as a Treatment for Chemotherapy-Induced Mucositis. Gut 62, 1724-1733. doi:10.1136/gutjnl-2012-303280

Kissow, H., Viby, N.-E., Hartmann, B., Holst, J. J., Timm, M., Thim, L., et al. (2012). Exogenous Glucagon-like Peptide-2 (GLP-2) Prevents Chemotherapy-Induced 
Mucositis in Rat Small Intestine. Cancer Chemother. Pharmacol. 70, 39-48. doi:10.1007/s00280-012-1882-2

Kolli, V. K., Abraham, P., Isaac, B., and Kasthuri, N. (2013). Preclinical Efficacy of Melatonin to Reduce Methotrexate-Induced Oxidative Stress and Small Intestinal Damage in Rats. Dig. Dis. Sci. 58, 959-969. doi:10.1007/s10620012-2437-4

Lalla, R. V., Choquette, L. E., Curley, K. F., Dowsett, R. J., Feinn, R. S., Hegde, U. P., et al. (2014). Randomized Double-Blind Placebo-Controlled Trial of Celecoxib for Oral Mucositis in Patients Receiving Radiation Therapy for Head and Neck Cancer. Oral Oncol. 50, 1098-1103. doi:10.1016/j. oraloncology.2014.08.001

Lee, J. B., Zhou, S., Chiang, M., Zang, X., Kim, T. H., and Kagan, L. (2020). Interspecies Prediction of Pharmacokinetics and Tissue Distribution of Doxorubicin by Physiologically-based Pharmacokinetic Modeling. Biopharm. Drug Dispos 41, 192-205. doi:10.1002/bdd.2229

Luo, R., Li, Y., He, M., Zhang, H., Yuan, H., Johnson, M., et al. (2017). Distinct Biodistribution of Doxorubicin and the Altered Dispositions Mediated by Different Liposomal Formulations. Int. J. pharmaceutics 519, 1-10. doi:10. 1016/j.jpharm.2017.01.002

Mao, Y., Nobaek, S., Kasravi, B., Adawi, D., Stenram, U., Molin, G., et al. (1996). The Effects of Lactobacillus Strains and Oat Fiber on Methotrexate- Induced Enterocolitis in Rats. Gastroenterology 111, 334-344. doi:10.1053/gast.1996. v111.pm8690198

Marchiando, A. M., Graham, W. V., and Turner, J. R. (2010). Epithelial Barriers in Homeostasis and Disease. Annu. Rev. Pathol. Mech. Dis. 5, 119-144. doi:10. 1146/annurev.pathol.4.110807.092135

Marchiando, A. M., Shen, L., Graham, W. V., Edelblum, K. L., Duckworth, C. A., Guan, Y., et al. (2011). The Epithelial Barrier Is Maintained by In Vivo Tight Junction Expansion during Pathologic Intestinal Epithelial Shedding. Gastroenterology 140, 1208-1218. doi:10.1053/j.gastro.2011.01.004

Monobe, M., Hino, M., Sumi, M., Uzawa, A., Hirayama, R., Ando, K., et al. (2005). Protective Effects of Melatonin on $\gamma$-ray Induced Intestinal Damage. Int. J. Radiat. Biol. 81, 855-860. doi:10.1080/09553000600554804

Mowat, A. M., and Agace, W. W. (2014). Regional Specialization within the Intestinal Immune System. Nat. Rev. Immunol. 14, 667-685. doi:10.1038/ nri3738

Nasilowska-Adamska, B., Rzepecki, P., Manko, J., Czyz, A., Markiewicz, M., Federowicz, I., et al. (2007). The Influence of Palifermin (Kepivance) on Oral Mucositis and Acute Graft versus Host Disease in Patients with Hematological Diseases Undergoing Hematopoietic Stem Cell Transplant. Bone Marrow Transpl. 40, 983-988. doi:10.1038/sj.bmt.1705846

Nicolatou-Galitis, O., Sarri, T., Sarri, T., Bowen, J., Di Palma, M., Kouloulias, V. E., et al. (2013). Systematic Review of Amifostine for the Management of Oral Mucositis in Cancer Patients. Support Care Cancer 21, 357-364. doi:10.1007/ s00520-012-1613-6

Novellasdemunt, L., Antas, P., and Li, V. S. W. (2015). Targeting Wnt Signaling in Colorectal Cancer. A Review in the Theme: Cell Signaling: Proteins, Pathways and Mechanisms. Am. J. Physiology-Cell Physiol. 309, C511-C521. doi:10.1152/ ajpcell.00117.2015

Nylander, O., and Sjöblom, M. (2007). Modulation of Mucosal Permeability by Vasoactive Intestinal Peptide or Lidocaine Affects the Adjustment of Luminal Hypotonicity in Rat Duodenum. Acta Physiol. 189, 325-335. doi:10.1111/j. 1748-1716.2006.01649.x

Odenwald, M. A., and Turner, J. R. (2017). The Intestinal Epithelial Barrier: a Therapeutic Target? Nat. Rev. Gastroenterol. Hepatol. 14, 9-21. doi:10.1038/ nrgastro.2016.169

Ohno, H. (2016). Intestinal M Cells. J. Biochem. 159, 151-160. doi:10.1093/jb/ mvv121

Patankar, J. V., and Becker, C. (2020). Cell Death in the Gut Epithelium and Implications for Chronic Inflammation. Nat. Rev. Gastroenterol. Hepatol. 17, 543-556. doi:10.1038/s41575-020-0326-4

Potten, C. S., Gandara, R., Mahida, Y. R., Loeffler, M., and Wright, N. A. (2009). The Stem Cells of Small Intestinal Crypts: where Are They? Cell Prolif. 42, 731-750. doi:10.1111/j.1365-2184.2009.00642.x

Prisciandaro, L. D., Geier, M. S., Butler, R. N., Cummins, A. G., and Howarth, G. S. (2011). Evidence Supporting the Use of Probiotics for the Prevention and Treatment of Chemotherapy-Induced Intestinal Mucositis. Crit. Rev. Food Sci. Nutr. 51, 239-247. doi:10.1080/10408390903551747
Quaresma, M., Damasceno, S., Monteiro, C., Lima, F., Mendes, T., Lima, M., et al. (2020). Probiotic Mixture Containing Lactobacillus Spp. And Bifidobacterium Spp. Attenuates 5-Fluorouracil-Induced Intestinal Mucositis in Mice. Nutr. Cancer 72, 1355-1365. doi:10.1080/01635581.2019.1675719

Rakhimova, O. (2010). [Use of Melatonin in Combined Treatment for Inflammatory Bowel Diseases]. Ter Arkh 82, 64-68.

Ranganathan, K., Simon, E., Lynn, J., Snider, A., Zhang, Y., Nelson, N., et al. (2018). Novel Formulation Strategy to Improve the Feasibility of Amifostine Administration. Pharm. Res. 35, 1-8. doi:10.1007/s11095-018-2386-5

Ribeiro, R. A., Wanderley, C. W. S., Wong, D. V. T., Mota, J. M. S. C., Leite, C. A. V. G., Souza, M. H. L. P., et al. (2016). Irinotecan- and 5-Fluorouracil-Induced Intestinal Mucositis: Insights into Pathogenesis and Therapeutic Perspectives. Cancer Chemother. Pharmacol. 78, 881-893. doi:10.1007/s00280-016-3139-y

Rigby, R. J., Carr, J., Orgel, K., King, S. L., Lund, P. K., and Dekaney, C. M. (2016). Intestinal Bacteria Are Necessary for Doxorubicin-Induced Intestinal Damage but Not for Doxorubicin-Induced Apoptosis. Gut microbes 7, 414-423. doi:10. 1080/19490976.2016.1215806

Salaga, M., Binienda, A., Draczkowski, P., Kosson, P., Kordek, R., Jozwiak, K., et al. (2018). Novel Peptide Inhibitor of Dipeptidyl Peptidase IV (Tyr-Pro-D-Ala$\mathrm{NH} 2$ ) with Anti-inflammatory Activity in the Mouse Models of Colitis. Peptides 108, 34-45. doi:10.1016/j.peptides.2018.08.011

Scarpignato, C., and Bjarnason, I. (2019). Drug-induced Small Bowel Injury: a Challenging and Often Forgotten Clinical Condition. Curr. Gastroenterol. Rep. 21, 1-12. doi:10.1007/s11894-019-0726-1

Sender, R., Fuchs, S., and Milo, R. (2016). Revised Estimates for the Number of Human and Bacteria Cells in the Body. PLoS Biol. 14, e1002533. doi:10.1371/ journal.pbio. 1002533

Siah, K. T. H., Wong, R. K. M., and Ho, K. Y. (2014). Melatonin for the Treatment of Irritable Bowel Syndrome. World J. Gastroenterol. 20, 2492. doi:10.3748/wjg. v20.i10.2492

Söderquist, F., Hellström, P. M., and Cunningham, J. L. (2015). Human Gastroenteropancreatic Expression of Melatonin and its Receptors MT1 and MT2. PloS one 10. e0120195. doi:10.1371/journal.pone.0120195

Sommansson, A., Nylander, O., and Sjöblom, M. (2013a). Melatonin Decreases Duodenal Epithelial Paracellular Permeability via a Nicotinic Receptor-dependent Pathway in Rats In Vivo. J. Pineal Res. 54, 282-291. doi:10.1111/jpi.12013

Sommansson, A., Saudi, W. S. W., Nylander, O., and Sjöblom, M. (2013b). Melatonin Inhibits Alcohol-Induced Increases in Duodenal Mucosal Permeability in Rats In Vivo. Am. J. Physiology-Gastrointestinal Liver Physiol. 305, G95-G105. doi:10.1152/ajpgi.00074.2013

Song, Y., Hu, W., Xiao, Y., Li, Y., Wang, X., He, W., et al. (2020). Keratinocyte Growth Factor Ameliorates Mycophenolate Mofetil-Induced Intestinal Barrier Disruption in Mice. Mol. Immunol. 124, 61-69. doi:10.1016/j.molimm.2020.04.012

Sonis, S., Elting, L., Elting, L., Keefe, D., Nguyen, H., Grunberg, S., et al. (2015). Unanticipated Frequency and Consequences of Regimen-Related Diarrhea in Patients Being Treated with Radiation or Chemoradiation Regimens for Cancers of the Head and Neck or Lung. Support Care Cancer 23, 433-439. doi:10.1007/s00520-014-2395-9

Sonis, S. T. (2009). Mucositis: the Impact, Biology and Therapeutic Opportunities of Oral Mucositis. Oral Oncol. 45, 1015-1020. doi:10.1016/j.oraloncology.2009. 08.006

Sonis, S. T., O'donnell, K. E., Popat, R., Bragdon, C., Phelan, S., Cocks, D., et al. (2004). The Relationship between Mucosal Cyclooxygenase-2 (COX-2) Expression and Experimental Radiation-Induced Mucositis. Oral Oncol. 40, 170-176. doi:10.1016/s1368-8375(03)00148-9

Soták, M., Mrnka, L., and Pácha, J. (2006). Heterogeneous Expression of Melatonin Receptor MT1 mRNA in the Rat Intestine under Control and Fasting Conditions. J. Pineal Res. 41, 183-188. doi:10.1111/j.1600-079x.2006.00355.x

Sougiannis, A. T., Vanderveen, B. N., Davis, J. M., Fan, D., and Murphy, E. A. (2021). Understanding Chemotherapy-Induced Intestinal Mucositis and Strategies to Improve Gut Resilience. Am. J. Physiology-Gastrointestinal Liver Physiol. [Epub ahead of print] doi:10.1152/ajpgi.00380.2020

Steinert, R. E., Feinle-Bisset, C., Asarian, L., Horowitz, M., Beglinger, C., and Geary, N. (2016). Ghrelin, CCK, GLP-1, and PYY(3-36): Secretory Controls and Physiological Roles in Eating and Glycemia in Health, Obesity, and After RYGB. Physiol. Rev. 97, 411-463. doi:10.1152/physrev.00031.2014

Stringer, A. M., Gibson, R. J., Bowen, J. M., Logan, R. M., Yeoh, A. S., and Keefe, D. M. (2009). Chemotherapy-induced Mucositis: The Role of Gastrointestinal 
Microflora and Mucins in the Luminal Environment. J Support Oncol. 5(6), 259-67.

Sugimoto, Y., and Narumiya, S. (2007). Prostaglandin E Receptors. J. Biol. Chem. 282, 11613-11617. doi:10.1074/jbc.r600038200

Sukhotnik, I., Geyer, T., Pollak, Y., Mogilner, J. G., Coran, A. G., and Berkowitz, D. (2014). The Role of Wnt/ $\beta$-Catenin Signaling in Enterocyte Turnover during Methotrexate-Induced Intestinal Mucositis in a Rat. PloS one 9, e110675. doi:10. 1371/journal.pone. 0110675

Thakkar, N. S., and Potten, C. S. (1992). Abrogation of Adriamycin Toxicity In Vivo by Cycloheximide. Biochem. Pharmacol. 43, 1683-1691. doi:10.1016/ 0006-2952(92)90697-h

Thorpe, D. (2019). The Role of Mucins in Mucositis. Curr. Opin. Support. Palliat. Care 13, 114-118. doi:10.1097/spc.0000000000000423

Touchefeu, Y., Montassier, E., Nieman, K., Gastinne, T., Potel, G., Bruley Des Varannes, S., et al. (2014). Systematic Review: the Role of the Gut Microbiota in Chemotherapy- or Radiation-Induced Gastrointestinal Mucositis - Current Evidence and Potential Clinical Applications. Aliment. Pharmacol. Ther. 40, 409-421. doi:10.1111/apt.12878

Tsai, C. H., Hill, M., Asa, S. L., Brubaker, P. L., and Drucker, D. J. (1997). Intestinal Growth-Promoting Properties of Glucagon-like Peptide-2 in Mice. Am. J. Physiology-Endocrinology Metab. 273, E77-E84. doi:10.1152/ajpendo.1997. 273.1.e77

Turini, M. E., and Dubois, R. N. (2002). Cyclooxygenase-2: a Therapeutic Target. Annu. Rev. Med. 53, 35-57. doi:10.1146/annurev.med.53.082901.103952

Vadhan-Raj, S., Goldberg, J. D., Perales, M. A., Berger, D. P., and Van Den Brink, M. R. (2013). Clinical Applications of Palifermin: Amelioration of Oral Mucositis and Other Potential Indications. J. Cell Mol Med 17, 1371-1384. doi: $10.1111 /$ jcmm.12169

van der Zanden, S. Y., Qiao, X., and Neefjes, J. (2020). New Insights into the Activities and Toxicities of the Old Anticancer Drug Doxorubicin. FEBS J. [Epub ahead of print]. doi:10.1111/febs.15583

Van Itallie, C. M., and Anderson, J. M. (2004). The Molecular Physiology of Tight Junction Pores. Physiology 19, 331-338. doi:10.1152/physiol.00027.2004

Villa, A., and Sonis, S. T. (2015). Mucositis: Pathobiology and Management. Curr. Opin. Oncol. 27, 159-164. doi:10.1097/cco.0000000000000180

Wang, L., Wang, R., Wei, G.-Y., Wang, S.-M., and Du, G.-H. (2020). Dihydrotanshinone Attenuates Chemotherapy-Induced Intestinal Mucositis and Alters Fecal Microbiota in Mice. Biomed. Pharmacother. 128, 110262. doi:10.1016/j.biopha.2020.110262

Wang, X., Gao, J., Qian, L., Gao, J., Zhu, S., Wu, M., et al. (2015). Exogenous IL-1Ra Attenuates Intestinal Mucositis Induced by Oxaliplatin and 5-fluorouracil through Suppression of P53-dependent Apoptosis. Anti-cancer drugs 26, 35-45. doi:10.1097/cad.0000000000000142

Wardill, H. R., Tissing, W. J. E., Kissow, H., and Stringer, A. M. (2019). Animal Models of Mucositis: Critical Tools for Advancing Pathobiological Understanding and Identifying Therapeutic Targets. Curr. Opin. Support. Palliat. Care 13, 119-133. doi:10.1097/spc.0000000000000421

Wehkamp, J., and Stange, E. F. (2020). An Update Review on the Paneth Cell as Key to Ileal Crohn's Disease. Front. Immunol. 11, 646. doi:10.3389/fimmu.2020. 00646
Wenqin, D., Yaodong, Z., Wanji, S., Fengli, Z., Li, S., Haili, J., et al. (2019). Armillariella Oral Solution Ameliorates Small Intestinal Damage in a Mouse Model of Chemotherapy-Induced Mucositis. Nutr. Cancer 71, 1142-1152. doi:10.1080/01635581.2019.1599029

Wu, Z.-Q., Han, X.-D., Wang, Y., Yuan, K.-L., Jin, Z.-M., Di, J.-Z., et al. (2011). Interleukin-1 Receptor Antagonist Reduced Apoptosis and Attenuated Intestinal Mucositis in a 5 -fluorouracil Chemotherapy Model in Mice. Cancer Chemother. Pharmacol. 68, 87-96. doi:10.1007/ s00280-010-1451-5

Wu, Z., Han, X., Qin, S., Zheng, Q., Wang, Z., Xiang, D., et al. (2010). Interleukin 1 Receptor Antagonist Reduces Lethality and Intestinal Toxicity of 5-fluorouracil in a Mouse Mucositis Model. Biomed. Pharmacother. 64, 589-593. doi:10.1016/ j.biopha.2010.06.006

Xiang, D.-C., Yang, J.-Y., Xu, Y.-J., Zhang, S., Li, M., Zhu, C., et al. (2020). Protective Effect of Andrographolide on 5-Fu Induced Intestinal Mucositis by Regulating P38 MAPK Signaling Pathway. Life Sci. 252, 117612. doi:10.1016/j. lfs.2020.117612

Yan, K. S., Gevaert, O., Zheng, G. X. Y., Anchang, B., Probert, C. S., Larkin, K. A., et al. 2017). Intestinal Enteroendocrine Lineage Cells Possess Homeostatic and Injury-Inducible Stem Cell Activity. Cell stem cell 21, 78-90.doi:10.1016/j.stem. 2017.06.014

Yasuda, M., Kato, S., Yamanaka, N., Iimori, M., Matsumoto, K., Utsumi, D., et al. (2013). 5-HT3receptor Antagonists Ameliorate 5-FluorouracilInduced Intestinal Mucositis by Suppression of Apoptosis in Murine Intestinal Crypt Cells. Br. J. Pharmacol. 168, 1388-1400. doi:10.1111/ bph.12019

Yeoh, A. S. J., Gibson, R. J., Yeoh, E. E. K., Bowen, J. M., Stringer, A. M., Giam, K. A., et al. (2007). A Novel Animal Model to Investigate Fractionated Radiotherapy-Induced Alimentary Mucositis: the Role of Apoptosis, P53, Nuclear Factor-кB, COX-1, and COX-2. Mol. Cancer Ther. 6, 2319-2327. doi:10.1158/1535-7163.mct-07-0113

Yeung, C.-Y., Chan, W.-T., Jiang, C.-B., Cheng, M.-L., Liu, C.-Y., Chang, S.-W., et al. (2015). Amelioration of Chemotherapy-Induced Intestinal Mucositis by Orally Administered Probiotics in a Mouse Model. PloS one 10, e0138746. doi:10.1371/journal.pone.0138746

Zhan, Y., Xu, C., Liu, Z., Yang, Y., Tan, S., Yang, Y., et al. (2016). $\beta$-Arrestin1 Inhibits Chemotherapy-Induced Intestinal Stem Cell Apoptosis and Mucositis. Cell Death Dis 7, e2229. doi:10.1038/cddis.2016.136

Conflict of Interest: The authors declare that the research was conducted in the absence of any commercial or financial relationships that could be construed as a potential conflict of interest.

Copyright $\odot 2021$ Dahlgren, Sjöblom, Hellström and Lennernäs. This is an openaccess article distributed under the terms of the Creative Commons Attribution License (CC BY). The use, distribution or reproduction in other forums is permitted, provided the original author(s) and the copyright owner(s) are credited and that the original publication in this journal is cited, in accordance with accepted academic practice. No use, distribution or reproduction is permitted which does not comply with these terms. 